\title{
PREVALENCE OF CHROMOSOMAL ABNORMALITIES IN INFERTILE COUPLES IN ROMANIA
}

\author{
Mierla $\mathrm{D}^{1, *}$, Malageanu $\mathrm{M}^{1}$, Tulin $\mathrm{R}^{1,2}$, Albu $\mathrm{D}^{1,2}$
}

*Corresponding Author: Dana Mierla, PhD, Department of Genetics, Life Memorial Hospital, Grivita Street, Bucharest, Romania. Tel: +40-72-147-9083. E-mail: dana_mierla@yahoo.com

\begin{abstract}
The purpose of this study was to establish a correlation between the presence of chromosomal abnormalities in one of the partners and infertility. This retrospective study was performed at the Department of Reproductive Medicine, Life Memorial Hospital, Bucharest, Romania, between August 2007 to December 2011. Two thousand, one hundred and ninety-five patients with reproductive problems were investigated, and the frequency of chromosomal abnormalities was calculated. The control group consisting of 87 fertile persons who had two or more children, was investigated in this retrospective study. All the patients of this study were investigated by cytogenetic techniques and the results of the two groups were compared by a twotailed Fisher's exact test. In this study, 94.99\% patients had a normal karyotype and 5.01\% had chromosomal abnormalities (numerical and structural chromosomal abnormalities). In the study group, numerical chromosomal abnormalities were detected in $1.14 \%$ of infertile men and $0.62 \%$ of infertile women, and structural chromosomal abnormalities were detected in $1.38 \%$ of infertile men and $1.87 \%$ of infertile women, respectively. The correlation between the incidence of chromosomal anomalies in the two sexes in couple with reproductive problems was not statistically significant.
\end{abstract}

\footnotetext{
$\overline{{ }^{1} \text { Department of Genetics, Life Memorial Hospital, Bucharest, }}$ Romania

${ }^{2}$ Department of Gynecology, Carol Davila University of Medicine and Pharmacy, Bucharest, Romania
}

Recently, a possible association between infertility and chromosomal abnormalities with a significant statistical association has been reported. Our study shows that there is no association between chromosomal abnormalities and infertility, but this study needs to be confirmed with further investigations and a larger control group to establish the role of chromosomal abnormalities in the etiology of infertility.

Keywords: Chromosomal abnormalities; chromosome polymorphisms; infertility

\section{INTRODUCTION}

Infertility is defined as the incapacity to conceive naturally after 1 year of regular unprotected sexual intercourse [1]. Infertility has become one of the most common medical problems, now affecting a large number of couples. The epidemiological data show that about $15.0 \%$ of the population are unable to conceive during the first year [2]. Most couples with infertility problems will conceive spontaneously or will be responsive to treatment, so that only $5.0 \%$ will remain incapable of conception [3].

In general, it is estimated that one in seven couples have conception problems, with a similar incidence in most countries, independent of their level of economical development [2]. The many factors that affect male and female infertility are: genetic, endocrine, environmental, lifestyle, infections.

Chromosomal abnormalities, one of the most frequent causes of genetic diseases, can be defined as a microscopic alteration of the chromosomes and 
may lead to reproductive failure in adults [4], to the occurrence of miscarriages and even to the death of the fetus. The frequency of chromosomal abnormalities is relatively high, major chromosomal abnormalities, including chromosomal polymorphisms, have been found in $1.3-15.0 \%$ of couples failing to conceive [511]. The most frequent chromosomal abnormalities are balanced chromosomal rearrangements (translocations), sex chromosomal mosaicism and inversions. Reciprocal translocations are one of the most common structural rearrangements observed in humans [11]. The individuals who carry this balanced translocation are clinically normal, but they do have an increased risk for having children with unbalanced karyotypes. Carriers of Robertsonian translocations are also at risk for miscarriages and for offspring with mental retardation and birth defects associated with aneuploidy.

Chromosomal abnormalities and genetic defects can determine failure of reproduction, and for this reason genetic analysis can play an important role in an infertility investigation. The incidence of autosomal chromosomal abnormalities in male infertility is $1.1-7.2 \%$ [12-15], and the incidence of chromosomal anomalies in women is $10.0 \%$ [16]. In our study, the incidence of chromosomal abnormalities was $2.52 \%$ in infertile men and $2.49 \%$ in infertile women.

\section{MATERIALS AND METHODS}

This is a retrospective study, performed at the Department of Reproductive Medicine, Life Memorial Hospital, Bucharest, Romania. In this study, cytogenetic analyses were performed on a population of 2195 patients with reproductive failures who were referred to our clinic for investigation between August 2007 and December 2011. The control group consisted of 87 fertile persons with one or two previous pregnancies (Table 1). Informed consent was obtained from the patients and controls prior to collection of blood samples with heparin as anticoagulant.

The blood samples were grown in culture medium (PB Max and chromosome B medium; Gibco/ Invitrogen, Grand Island, NY, USA) for 72 hours, and processed using GTG banding techniques. For each case, 10 metaphases were analyzed in accordance with the International System for Human Cytogenetic Nomenclature (ISCN) 2013 [17]. The banding resolution was 400-550 band per haploid set (BPHS). Molecular cytogenetic methods were also used [metaphase and interphase fluorescent in situ hybridization (FISH)].

Statistical Analysis. The results of the two groups were compared using the two-tailed Fisher's exact test and calculated with GraphPad Software

Table 1. Characteristics of the studied groups.

\begin{tabular}{|l|c|l|c|}
\hline Study Group $(\boldsymbol{n})$ & Study Period & \multicolumn{1}{|c|}{ Group Description } & Age (range in years) \\
\hline Infertile men $(n=1231)$ & $2007-2011$ & azoospermia; oligospermia; OATS & $35.40(26-50)$ \\
\hline Infertile women $(n=964)$ & $2007-2011$ & miscarriage; abortive disease; sterility & $27.81(21-38)$ \\
\hline Controls: fertile men $(n=35)$ & $2010-2011$ & normal spermogram; 1-2 births & $32.09(25-42)$ \\
\hline Controls: fertile women $(n=52)$ & $2010-2011$ & $1-2$ births & $31.19(22-40)$ \\
\hline
\end{tabular}

OATS: oligoasthenoteratozoospermia.

Table 2. Identified chromosomal anomalies in the infertile men and the control group.

\begin{tabular}{|l|c|c|c|}
\hline Patients & $\begin{array}{c}\text { Autosomal Anomalies } \\
\boldsymbol{n}(\mathbf{\%})\end{array}$ & $\begin{array}{c}\text { Sex Chromosome Anomalies } \\
\boldsymbol{n}(\mathbf{\%})\end{array}$ & $\begin{array}{c}\text { Total } \\
\boldsymbol{( \% )}\end{array}$ \\
\hline Study group $(n=1231)$ & $17(1.38)$ & $14(1.14)$ & $31(2.52)$ \\
\hline OATS $(n=700)$ & $5(0.71)$ & $2(0.29)$ & $7(1.00)$ \\
\hline Azoospermia $(n=150)$ & $3(2.0)$ & $8(5.33)$ & $11(7.33)$ \\
\hline Oligozoospermia $(n=50)$ & $1(2.0)$ & $1(2.0)$ & $2(4.0)$ \\
\hline Oligoteratozoospermia $(n=10)$ & $1(10.0)$ & - & $1(10.0)$ \\
\hline Oligoasthenospermia $(n=21)$ & $1(4.76)$ & - & $1(4.76)$ \\
\hline Normospermia $(n=300)$ & $6(2.0)$ & $3(1.0)$ & $9(3.0)$ \\
\hline Control group $(n=35)$ & - & - & - \\
\hline
\end{tabular}

OATS: oligoasthenoteratozoospermia 
(http://www.graphpad .com/quickcalcs/contingency1.cfm8).

\section{RESULTS}

One thousand, two hundred and thirty-one infertile men were investigated by classical cytogenetic techniques. Of these, 700 men presented with aligoasthenoteratozoospermia (OATS), 150 azoospermia, 50 oligozoospermia, 10 oligoteratozoospermia, 21 oligoasthenospermia and 300 with normospermia. The control group consisted of 35 fertile men with one or more children. The chromosomal abnormalities identified in the control group and the study group are presented in Table 2 .

The male factor is responsible for approximately $40.0 \%$ of infertility cases [18]. Chromosomal abnor- malities are an important cause of male infertility. The incidence of chromosomal abnormalities in infertile men was $2.52 \%$, of which $1.38 \%$ were autosomal abnormalities and $1.14 \%$ sex chromosomal abnormalities. No chromosomal abnormalities were identified in the control group (Table 2).

A total of 964 women with reproductive problems were investigated by classical cytogenetic techniques. Three hundred and fifty had one previous miscarriage, 300 had two miscarriages, 150 had three or more miscarriages and 164 had a history of sterility or abortive disease. The control group consisted of 52 fertile women with one or more children. The chromosomal abnormalities identified in the two groups are presented in Table 3. The incidence of chromosomal abnormalities in our group was $2.49 \%$, of which $1.87 \%$ were autosomal abnormalities and

Table 3. Identified chromosomal in the infertile women and control group.

\begin{tabular}{|l|c|c|c|}
\hline Patients & $\begin{array}{c}\text { Autosomal Anomalies } \\
\boldsymbol{n}(\mathbf{\%})\end{array}$ & $\begin{array}{c}\text { Sex Chromosome } \\
\text { Anomalies } \boldsymbol{n}(\mathbf{\%})\end{array}$ & $\begin{array}{c}\text { Total } \\
\boldsymbol{n}(\mathbf{\%})\end{array}$ \\
\hline Study group $(n=964)$ & $18(1.87)$ & $6(0.62)$ & $24(2.49)$ \\
\hline History of spontaneous abortions $(n=350)$ & $3(0.86)$ & - & $3(0.86)$ \\
\hline History of two miscarriages $(n=300)$ & $4(1.33)$ & - & $4(1.33)$ \\
\hline Three or more spontaneous abortions $(n=50)$ & $8(5.33)$ & - & $8(5.33)$ \\
\hline Sterility (abortive disease) $(n=164)$ & $3(1.83)$ & $6(3.66)$ & $9(5.49)$ \\
\hline Control group $(n=52)$ & $1(1.92)$ & - & $1(1.92)$ \\
\hline
\end{tabular}

Table 4. Major chromosomal anomalies identified in infertile men.

\begin{tabular}{|c|c|c|c|c|}
\hline & Chromosomal Anomalies & Karyotype & $n$ & $\%$ \\
\hline \multirow[t]{3}{*}{$\begin{array}{l}\text { Structural chromosomal } \\
\text { anomalies }\end{array}$} & Inversions & $\begin{array}{l}\text { 46,XY,inv(1)(q23p13) } \\
\text { 46,XY,inv(1)(q13p31) } \\
\text { 46,XY,inv(5)(pterq13) } \\
\text { 46,XY,inv(10)p11.2q21) }\end{array}$ & $\begin{array}{l}1 \\
1 \\
1 \\
1\end{array}$ & $\begin{array}{l}0.08 \\
0.08 \\
0.08 \\
0.08\end{array}$ \\
\hline & Deletions & $\begin{array}{l}\text { 46,X,del(Y)(q11.2) } \\
46, \mathrm{Xdel}(\mathrm{Y})(\mathrm{q} 12)\end{array}$ & $\begin{array}{l}1 \\
1\end{array}$ & $\begin{array}{l}0.08 \\
0.08\end{array}$ \\
\hline & Translocations & 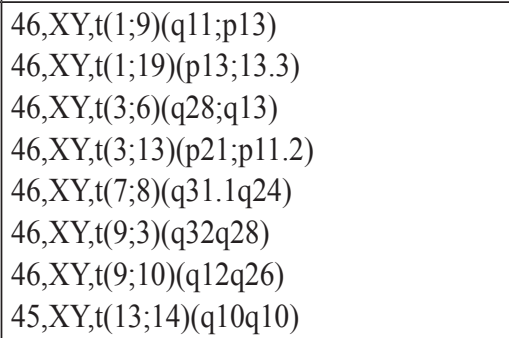 & $\begin{array}{l}1 \\
2 \\
1 \\
1 \\
1 \\
1 \\
1 \\
5\end{array}$ & $\begin{array}{l}0.08 \\
0.16 \\
0.08 \\
0.08 \\
0.08 \\
0.08 \\
0.08 \\
0.41\end{array}$ \\
\hline $\begin{array}{l}\text { Numerical chromosomal } \\
\text { anomalies }\end{array}$ & $\begin{array}{l}\text { Klinefelter syndrome } \\
\text { syndrome 47,XYY } \\
\text { syndrome 46,XX } \\
\text { mosaicism } \\
\text { isochromosome }\end{array}$ & $\begin{array}{l}47, \mathrm{XXY} \\
47, \mathrm{XYY} \\
46, \mathrm{XX} \\
\operatorname{mos} 47, \mathrm{XXY}, 22 \mathrm{ps}+[15] / 46, \mathrm{XY}, 22 \mathrm{ps}+[5] \\
46, \mathrm{X}, \mathrm{i}(\mathrm{Yp})\end{array}$ & $\begin{array}{l}5 \\
2 \\
3 \\
1 \\
1\end{array}$ & $\begin{array}{l}0.41 \\
0.16 \\
0.24 \\
0.08 \\
0.08\end{array}$ \\
\hline
\end{tabular}


$0.62 \%$ sex chromosomal abnormalities. The incidence of chromosomal abnormalities in the control group was 1.92\% (autosomal abnormalities.

Numerical and structural chromosomal abnormalities identified in infertile patients are presented in Tables 4 and 5. In this study, we did a correlation between the incidence of chromosomal anomalies identified in infertile men compared to infertile women and found that there was no statistical significance (Table 6). Cytogenetic analysis revealed a number of chromosomal polymorphisms, considered as normal chromosomal variations, but they have not been investigated in this study.

\section{DISCUSSION}

In recent years, more and more studies have shown an increased incidence of chromosomal abnormalities in couples with reproductive disorders $[18,19]$. Our study was designed to explore the implication of chromosomal abnormalities in infertility in men and women. In this study, the incidence of chromosomal abnormalities in infertile couples is similar to other studies $(2.52 \%$ in men and $2.49 \%$ in women). In our study, the autosomal chromosomal abnormalities consisted of translocations (reciprocal, Robertsonian) and inversions. Autosomal transloca-

Table 5. Major chromosomal anomalies identified in infertile women.

\begin{tabular}{|c|c|c|c|c|}
\hline & Chromosomal Anomalies & Karyotype & $n$ & $\%$ \\
\hline \multirow[t]{3}{*}{$\begin{array}{l}\text { Structural chromosomal } \\
\text { anomalies }\end{array}$} & Inversions & $\begin{array}{l}\text { 46,XX,inv(1)(q13p31) } \\
\text { 46,XX,inv(5)(pterq13) } \\
\text { 46,XX,inv(8)(p22q13) }\end{array}$ & $\begin{array}{l}2 \\
2 \\
2\end{array}$ & $\begin{array}{l}0.21 \\
0.21 \\
0.21\end{array}$ \\
\hline & Duplications & $\begin{array}{l}\text { 46,XX,dup(18p) } \\
\text { 46,XX,var(9)dup(9)(q13q21.12) }\end{array}$ & $\begin{array}{l}1 \\
1\end{array}$ & $\begin{array}{l}0.10 \\
0.10\end{array}$ \\
\hline & Translocations & $\begin{array}{l}\text { 46,XX,t(1;10)(q41;p14) } \\
46, X X, t(4 ; 13)(\mathrm{p} 11 ; \mathrm{q} 11) \\
46, \mathrm{XX}, \mathrm{t}(4 ; 22)(\mathrm{p} 13 ; \mathrm{q} 12) \\
46, \mathrm{XX}, \mathrm{t}(9 ; 22)(\mathrm{q} 34 \mathrm{q} 11) \\
\\
46, \mathrm{XX}, \mathrm{t}(10 ; 19)(\mathrm{q} 22 \mathrm{q} 13) \\
46, \mathrm{XX,t}(13 ; 16)(\mathrm{q} 13 ; \mathrm{q} 12) \\
46, \mathrm{XX}, \mathrm{t}(15 ; 18)(\mathrm{q} 26 ; 12) \\
46, \mathrm{XX}, \mathrm{t}(14 ; 15)(\mathrm{q} 10 \mathrm{q} 10) \\
46, \mathrm{XX}, 1 \mathrm{qh}+\mathrm{t}(1 ; 4)(\mathrm{q} 43 ; \mathrm{p} 13) \\
46, \mathrm{XX}, \mathrm{t}(3 ; 11)(\mathrm{p} 25 ; \mathrm{q} 22) ; \operatorname{inv}(9)(\mathrm{p} 11 \mathrm{q} 12)\end{array}$ & $\begin{array}{l}1 \\
1 \\
1 \\
1 \\
1 \\
1\end{array}$ & $\begin{array}{l}0.10 \\
0.10 \\
0.10 \\
0.10 \\
0.10 \\
0.10 \\
0.10 \\
0.10 \\
0.10 \\
0.10\end{array}$ \\
\hline $\begin{array}{l}\text { Numerical chromosomal } \\
\text { anomalies }\end{array}$ & $\begin{array}{l}\text { Turner syndrome } \\
\text { syndrome 46,XY }\end{array}$ & $\begin{array}{l}45, \mathrm{X} \\
46, \mathrm{XX}[5] / 45, \mathrm{X}[10] / 46, \mathrm{Xi}(\mathrm{Y})[8] \\
45, \mathrm{X}[16] / 46, \mathrm{Xi}(\mathrm{X})[4] \\
46, \mathrm{XX}[5] / 45, \mathrm{X}[7] / 46, \mathrm{XY}[10] \\
46, \mathrm{X}, \mathrm{i}(\mathrm{Xq}) \\
46, \mathrm{XY}\end{array}$ & $\begin{array}{l}1 \\
1 \\
1 \\
1 \\
1 \\
1\end{array}$ & $\begin{array}{l}0.10 \\
0.10 \\
0.10 \\
0.10 \\
0.10 \\
0.10\end{array}$ \\
\hline
\end{tabular}

Table 6. Correlation between the incidence of chromosomal anomalies in the two sexes in couples with reproductive problems.

\begin{tabular}{|l|c|c|c|c|}
\hline Chromosomal Anomalies & $\begin{array}{c}\text { Infertile Men } \\
\boldsymbol{n = 1 2 3 1}(\mathbf{\%})\end{array}$ & $\begin{array}{c}\text { Infertile Women } \\
\boldsymbol{n = 9 6 4}(\mathbf{\%})\end{array}$ & $\chi^{\mathbf{2}}$ & $\boldsymbol{p}$ Value \\
\hline Inversions & $4(0.32)$ & $6(0.62)$ & 1.040 & 0.30 \\
\hline Duplications & $0(0.00)$ & $2(0.21)$ & 2.556 & 0.10 \\
\hline Deletions & $2(0.16)$ & $0(0.00)$ & 1.568 & 0.21 \\
\hline Translocations & $13(1.06)$ & $10(1.04)$ & 0.020 & 0.96 \\
\hline Numerical chromosomal anomalies & $8(0.65)$ & $3(0.31)$ & 1.244 & 0.26 \\
\hline Chromosomal gaps & $1(0.08)$ & $0(0.00)$ & 0.783 & 0.37 \\
\hline
\end{tabular}


tions were found in $1.06 \%$ of the infertile patients (13 patients), $0.68 \%$ (eight cases) were reciprocal translocations between different chromosomes and $0.41 \%$ (five men) were Robertsonian translocations. Within this group, the Robertsonian translocation $[\mathrm{t}(13 ; 14)(\mathrm{q} 10 ; \mathrm{q} 10)]$ is the most frequent translocation observed in infertile men (0.41\%) [8]. Translocations between group D chromosomes represent approximately $75.0 \%$ of all Robertsonian translocations [20]. The chromosomal abnormalities play a determining role in infertility with an incidence between 10.0 and $15.0 \%$ [21]. The incidence of chromosomal abnormalities in this study is similar to other studies.

The identified chromosomal abnormalities at the sex chromosome level are most frequently associated with male infertility. The prevalence of the Klinefelter syndrome is $0.6-1.0 \%$ in the general population and up to $10.0 \%$ in male infertility [21-23]. In this study, sex chromosomal abnormalities were found in 14 infertile men (1.14\%), five with Klinefelter syndrome $(47, \mathrm{XXY})$, a syndrome associated with severe disturbance of the spermatogenesis; two patients with oligozoospermia presented the karyotype $47, \mathrm{XYY}$, three had karyotype 46,XX, two had 46,X,delY(q), one had an isochromosome of the short arm of chromosome $\mathrm{Y}$ and one patient had the normal chromosomal mosaicism 47,XXY,22ps+[15]/46,XY,22ps+[5]. Of the patients with sex chromosomal abnormalities, $3.0 \%$ had an infertility from an unknown cause. In this study, Klinefelter syndrome represents one of the most frequent causes of male infertility, similar to the data in the literature [21]. The XYY syndrome is also a common chromosomal abnormality, most men being fertile, but there are also studies suggesting an association with infertility. In this study, we found two patients with this syndrome and one case of cellular mosaicism 47,XXY,22ps+[15]/ 46,XY,22ps+[5] [21].

After Klinefelter syndrome, Yq deletions are also a frequent cause of male infertility [24]. Anomalies of the $\mathrm{Y}$ chromosome have been found in this study in three $(1.0 \%)$ patients with infertility of an unknown cause. Two of these had a deletion of the long arm of the $\mathrm{Y}$ chromosome and one had an isochromosome of the short arm of chromosome Y. There were also three reported cases of the XX syndrome in infertile men, with an incidence of $0.24 \%$. In all these cases, the mechanism explaining the male phenotype was translocation of the $S R Y$ gene on an X chromosome
[13]. This was observed following the interphase and metaphase FISH on the cytogenetic preparations.

A high prevalence of chromosomal anomalies $(6.0 \%)$ was also observed in patients with a history of miscarriages. The genetic etiology for miscarriages includes an unbalanced chromosomal rearrangement that may be the result of a reciprocal translocation in one of the partners [25]. Miscarriages represent an essential cause of female infertility. They can be caused by chromosomal abnormalities such as reciprocal or Robertsonian translocations, as well as by other chromosomal aberrations such as inversions on chromosome 9. The incidence of chromosomal abnormalities in the studied group of infertile women was $2.49 \%$, which is similar to several studies [18]. In 2002, Raziel et al. [13] found an incidence of chromosomal abnormalities in $14.5 \%$ of patients. In our study, $1.87 \%$ of these abnormalities were autosomal and $0.62 \%$ were sex chromosomal abnormalities. Autosomal abnormalities consisted of translocations between different groups of chromosomes, inversions and duplications. Inversions, translocations and duplications seem to be associated with miscarriages. In this study group, inversions were identified at chromosomes 1,5 and 8 in six patients with a history of miscarriages. The incidence of these pericentric inversions was $0.62 \%$. In 10 cases, autosomal reciprocal translocations were identified at chromosomes $1,3,4,9,10,13,15,16,18,19$ and 22 , with an incidence of $1.04 \%$, similar to some studies [10]. In this study group, Robertsonian translocations have been found at a reduced frequency $(0.10 \%)$. The incidence of Robertsonian translocations in female infertility is higher than in this study (0.69\%) [10]. In 2001, Gekas et al. [10] conducted a study in 1012 infertile women enrolled in the Intracytoplasmatic Sperm Injection (ICSI) program. They observed an incidence of $4.84 \%$ of chromosomal abnormalities, where reciprocal and Robertsonian translocations $(0.69 \%)$ and inversions $(0.69 \%)$, had the highest frequencies [10].

In the group of fertile patients, one case of reciprocal translocation with the chromosomal karyotype $46, X X, t(13 ; 16)(q 33.3 ; p 12.2)$ was identified. The childrens' karyotypes were also determined and it was found that one of the children presented the same structural modification as the mother, the other having a normal karyotype.

The chromosomal abnormalities identified at the sex chromosome were found in six infertile women 
$(0.62 \%)$, three (o.31\%) women were diagnosed with the Turner syndrome in mosaic, one patient $(0.10 \%)$ presented karyotype $45, X$, another $(0.10 \%)$ karyotype $46, \mathrm{Xi}(\mathrm{Xq})$, and yet another $(0.10 \%)$ presented karyotype 46,XY (syndrome 46,XY in women). Turner syndrome is one of the most frequent chromosomal abnormalities (1/2500 female newborns). The presence of the $\mathrm{Y}$ chromosome was detected in $6.0 \%$ of the cases through karyotyping and up to $60.0 \%$ throug molecular diagnostics [26]. These patients were also examined using cytogenetic molecular techniques (metaphase and interphase FISH), which led to the observation of the presence of the characteristic signal for chromosomes $\mathrm{X}$ and $\mathrm{Y}$, respectively.

Of the identical chromosomal abnormalities in the two groups, we point out the structural abnormalities $(1.38 \%$ of men and $1.87 \%$ of women) and the numerical abnormalities (1.14\% of men and $0.62 \%$ of women). Linking the present chromosomal abnormalities of the two sexes did not lead to any statistical significance $(p=0.96)$.

\section{CONCLUSIONS}

Chromosomal anomalies and genetic defects can determine reproductive failure. For this reason, genetic analysis can play a decisive role in infertile couples. The percentage of chromosomal abnormalities was higher in the group of infertile men in comparison with the infertile women, but there was not statistical significance regarding the implication of chromosomal abnormalities in infertility in men and women. This study needs to be confirmed with further investigations and a larger control group to establish the role of chromosomal aberrations in the etiology of infertility.

Declaration of Interest. This study was performed with support from the Department of Reproductive Medicine, Life Memorial Hospital, Bucharest, Romania. The authors report no conflicts of interest. The authors alone are responsible for the content and writing of this article.

\section{REFERENCES}

1. Rowe PJ, Comhaire FH. World Health Organization manual for the standardised investigation and diagnosis of infertile couples. Current prac- tices and controversies in assisted reproduction. Cambridge, UK: Cambridge University Press. 2002: 14-15.

2. Azimi C, Khaleghian M, Farzanfar F. A retrospective chromosome studies among Iranian infertile women: Report of 21 years. Iran J Reprod Med. 2013; 11(4): 315-324.

3. Taylor A, Braude P. ABC of subfertility. Extent of the problem. BMJ Publishing Group. 2008: 1-4.

4. Dada R, Gupta NP, Kucheria K. Cytogenetic and molecular analysis of male infertility. Cell Biochem Biophys. 2006; 44(1): 171-177.

5. Akgul M, Ozkinay F, Ercal D. Cytogenetic abnormalities in 179 cases with male infertility in western region of Turkey: Report and review. J Assist Reprod Genet. 2009; 6(2-3): 119-122.

6. Balkan M, Tekes S, Gedik A. Cytogenetic and Y chromosome microdeletion screening studies in infertile males with oligozoospermia and azoospermia in Southeast Turkey. J Assist Reprod Genet. 2008; 25(11-12): 559-565.

7. Azimi C, Khaleghian M, Farzanfar F. Cytogenetic studies among Iranian infertile men: The first 20-year long-term report. Afr J Biotechnol. 2012; 11(37): 8973-8978.

8. Clementini E, Palka C, Iezzi I, Stuppia L, Guanciali-Franchi P, Tiboni GM. Prevalence of chromosomal abnormalities in 2078 infertile couples referred for assisted reproductive techniques. Hum Reprod. 2005; 20(2): 4327-4442.

9. Rosenbusch B. Somatic chromosomal abnormalities in couples undergoing infertility treatment by intracytoplasmic sperm injection. J Genet. 2010; 89(1): 105-108.

10. Gekas J, Thepot F, Turleau C, Siffroi JP, Dadoune JP, Wasels R, et al. Chromosomal factors of infertility in candidate couples for ICSI: An equal risk of constitutional aberration in women and men. Hum Reprod. 2001; 16(1): 82-90.

11. Gersen SL, Keagle MB. Human chromosome nomenclature. An overview and definition in terms. The Principles of Clinical Cytogenetics. Totowa, New Jersey: Humana Press. 2005: 541-544.

12. Elghezal H, Hidar S, Braham R, Denguezli W, Ajina M, Saâd A. Chromosome abnormalities in one thousand infertile males with nonobstructive sperm disorders. Fertil Steril. 2006; 86(6): 1792-1795. 
13. Raziel A, Friedler S, Schachter M, Kastertein E, Strassburger D, Ron-El R. Increased frequency of female partner chromosomal abnormalities in patients with high-order implantation failure after in vitro fertilization. Fertil Steril. 2002; 78(3): 515-519.

14. Yatsenko AN, Yatsenko SA, Weedin JW, Lawrence AE, Patel A, Peacock S, et al. Comprehensive 5-year study of cytogenetic aberrations in 668 infertile men. J Urol. 2010; 183(4): 1632-1642.

15. Ravel C, Berthant I, Bresson JL, Siffroi JP. Prevalence of chromosomal abnormalities in phenotypically normal and fertile adult males: Large-scale survey for over 10000 sperm donor karyotypes. Hum Reprod. 2006; 21(6): 1484-1489.

16. Vicdan A, Vicdan K, Gunalp S, Kence A, Akarsu $\mathrm{C}$, Isik AZ, et al. Genetic aspects of human male infertility: The frequencies of chromosomal abnormalities and $\mathrm{Y}$ chromosome microdeletions in severe male factor infertility. Eur J Obstet Gynecol Reprod Biol. 204; 117(1): 49-54.

17. Shaffer LG, McGowan J, Schmid M. ISCN 2013 An international system for human cytogenetic nomenclature. Published in collaboration with Cytogenetic and Genome Research, Karger, 2013.

18. Al-Achkar W, Wafa A, Moassass F. Cytogenetic abnormalities and Y-chromosome microdeletions in infertile Syrian males. Biomed Reports. 2013; 1(2): 275-279.

19. Jungwirth A, Diemer T, Dohle GR, Giwercman A, Kopa Z, Krausz C, et al. Guidelines on Male Infertility. European Association of Urology, 2012.
20. Scriven PN, Flinter FA, Braude PR, Ogilvie CM. Robertsonian translocations - Reproductive risks and indications for preimplantation genetic diagnosis. Hum Reprod. 2001; 16(11): 2267-2273.

21. Bellovits O, Rusz A, Romics I, Csonka E, Hadlaczky G. Chromosomal aneuploidy in azoospermic men. PéterInt J Hum Genet. 2006; 6(2): 171-176.

22. Lanfranco F, Kamischke A, Zitzmann M, Nieschlag E. Klinefelter's syndrome. Lancet. 2004; 364(9430): 273-283.

23. Mierla D, Jardan D, Stoian V. Chromosomal abnormality in men with impaired spermatogenesis. Int J Fertil Steril. 2014; 8(1): 35-42.

24. Poongothai J, Gopenath TS, Manonayaki S. Genetics of human male fertility. Singapore Med J. 2009; 50(4): 336-347.

25. Mozdarani H, Mohseni Meybody A, Zari-Moradi S. A cytogenetic study of couples with recurrent spontaneous abortions and infertile patients with recurrent IVF/ICSI failure. Indian J Hum Genet. 2008; 14(1): 1-6.

26. Guimarães J, Almeida Santos T, Barbosa A, Bastos M, Almeida Santos A, Carvalheiro M. Screening for gene SRY by FISH in patients with Turner syndrome. Endocrine Abstracts. 2006; 11P: 720. 
